of the Upper Air appointed a sub-commission to consider the problem set out above, and the subcommission applied to various Ministries of War with the view of obtaining their collaboration in the case of obligatory destruction of explosives. The first favourable reply came from the Dutch Ministry of War, and it was finally arranged that at $\mathrm{I} 7 \mathrm{~h}$. G.M.T. on October 28, five tons of ammonium perchlorate should be exploded on the Oldebroek Artillery Drill Ground (longitude $5^{\circ} 59^{\prime} 40^{\prime \prime}$; latitude $\left.52^{\circ} 29^{\prime} 56^{\prime \prime}\right)$.

In this country arrangements were made by the Meteorological Office for the observers at all the observatories and reporting stations to listen for the sound, and to make notes regarding the meteorological conditions at the time. Where possible, observations of wind and temperature in the upper air were also made. In addition, through the medium of the Press, the public were also invited to forward to the Meteorological Office notes of any observations made.

Up to the time of going to press a total of more than one hundred reports have been received and it has not yet been possible to examine them in detail. The most distant points at which the explosion is alleged to have been heard are North. Wales and Northumberland. Two valuable records have been obtained on the hot wire microphones of the Signals Experimental Establishment, at Woolwich, and at Biggin Hill (Kent) respectively.

As soon as the British observations have been examined and summarised, the results will be forwarded to the Dutch Meteorological Service for collation with continental reports.

\section{The Whitworth Scholarships.}

SEVERAL important changes are indicated in the new regulations for Whitworth Scholarships which have been issued by the Board of Education. In 1923 six Whitworth Scholarships, each of an annual value of $125 l$. and tenable for three years, will be offered for competition, as well as two Whitworth Senior Scholarships of an annual value of $250 l$., tenable for two years. There are also Whitworth prizes which will be awarded to unsuccessful competitors for the scholarships, not exceeding 25 in number and of value rol. each. The Whitworth Exhibitions (5ol. tenable for one year) have been abandoned. The scholarships will be open to candidates whose age does not exceed $2 \mathrm{I}$ years, and the number of subjects in which candidates will be examined is limited to four. Candidates for the senior scholarships must be less than 26 years of age and will be examined in seven subjects.

The Board has also issued a circular directing attention to the changes, some of which were made last year, in order to render the requirements regarding candidates' practical experience in handicraft more consistent with the present arrangements for apprenticeship and training in mechanical engineering. The Board's experience shows that candidates may be divided into two groups, a large one consisting of candidates whose education since leaving school has been part-time, and for whom a full-time course of study is likely to be suitable, and a smaller one consisting of those who have already completed a full-time course and can take a further course of work of post-graduate standard. Hence the institution of scholarships and senior scholarships.

There still remain difficulties which the new regulations will not remove. In the four years between I7 and $2 I$ years of age a hard-working evening student can reach the ordinary university degree standard in the subjects laid down for the scholarship examinations, but has only touched lightly certain subjects which form part of any organised full-time course. If a scholarship is awarded to him, and he proceeds to a full-time course, he will find that he cannot be exempted from repeating a great deal with which he is perfectly familiar. This difficulty is a very real one, as is well known to every teacher who has been consulted by a successful Whitworth candidate regarding his choice of a suitable college. There is also the difficulty of finding a suitable opening in the works after having been away for three years between the ages of $2 \mathrm{I}$ and 24, a difficulty which has led to many promising young men abandoning practical life in favour of teaching.

The circulars issued by the Board convey the impression that they do not favour the plan followed by many of the former scholars, who spent their scholarship term in works offering special facilities for widening their practical experience, and at the same time continued their studies in part-time courses. There is a great deal to be said in favour of this plan, and a glance at the names of former scholars who followed it and have risen to eminence in engineering would appear to justify its reconsideration.

\section{University and Educational Intelligence.}

BrIsTol.-The Bristol Medico-Chirurgical Society has offered the society's library as a gift to the University. The library comprises about I $_{5}, 000$ volumes (some rare and of great interest) and has been valued at more than $\mathrm{r} 2,00 \mathrm{l}$. It contains some rare books and receives more than Ioo current periodicals in exchange for the society's journal. The council of the University has very gratefully accepted this magnificent offer, which will raise the medical library of the University to one of the most valuable medical libraries in the country. The advantage to the research worker of having access to such a library cannot be over-estimated.

Cambridge.-Mr. R. E. Priestley, Christ's College, has been elected to a fellowship at Clare College; Mr. M. C. Johnson, St. John's College, has been elected to the Arnold Gerstenberg studentship; Mr. N. J. T. M. Needham, Gonville and Caius College, has been elected to the Benn W. Levy research studentship in biochemistry.

The Syndicate appointed to draft Ordinances to carry out the provisions of the new statute admitting women students to the titles of degrees has been published. It is proposed to recognise Girton and Newnham Colleges as institutions for the higher education of women for the purposes of the statute. The total number of students at the two colleges (or at all institutions for the higher education of women, should any fresh college be recognised) who are receiving instruction in the University or working in the University laboratories or museums is not to exceed five hundred. The Council of the Senate may at any time inquire into the condition and management of a recognised institution for the higher education of women, and may, if it think fit, recommend the termination of its recognition. Women must reside nine terms, and in other such matters come under the same regulations as the undergraduates before admission to the titles of their degrees. Once the title has been conferred upon them, they become entitled to wear the same academical dress as that worn by a member of the University who has been admitted to the same degree. Women are to be admitted to courses of research and to examinations for diplomas sub-

$$
\text { NO. } 2766 \text {, vOL. I } 10]
$$

